\title{
Rhythms and causalities of the anthropisation dynamics in Europe between 8500 and 2500 cal BP: Sociocultural and/or climatic assumptions
}

This issue of Quaternary International is the proceedings volume of a session of the UISPP Conference held at Lisbon in September 2006. This session focused on the rhythms and causalities of the anthropisation dynamics in Europe between 8500 and $2500 \mathrm{cal}$ BP, i.e. during the Neolithic and Protohistoric periods. In a natural perspective, one of the special interests of the Holocene for the history of the European landscapes is to offer the opportunity to observe the evolution of ecosystems under the influence of both natural and human factors, that is to say climate forcing and changes initiated by the Mesolithic-Neolithic transition. Conversely, in a human perspective, the Holocene also gives the opportunity to examine the driving forces of the history of the first agricultural societies, and to disentangle sociocultural and climatic factors.

Most of the nine papers in this volume document the Mediterranean area. G. Jalut proposes a general overview of the Holocene circum-Mediterranean vegetation changes. On the basis of a comparison between pollen and various palaeoclimatic records, the Holocene is divided into three periods: a lower humid Holocene (11,500-7000 cal BP), a transition phase (7000-5500 cal BP), and an upper Holocene $(5500$ cal BP-present) marked by an aridification process. He concludes that climatic changes (orbital forcing) were the major determining factor of the evolution of Mediterranean landscapes. Societies had to adapt to natural environmental variations, but since the Roman period, a strong human impact may have accentuated the effects of climatic constraints.

On the basis of pollen data, the second paper by A. Bordon et al. presents a quantitative palaeoclimatic record for the Lateglacial and Holocene from Lake Maliq in Albania. In particular, the results demonstrate changes in the seasonality of precipitation, with summer precipitation more abundant during cold phases than during temperate periods. The Holocene appears to be relatively stable except for a marked cool and arid event between 8300 and 8100 cal BP.

The work by J.F. Berger and J. Guilaine reports on the possible impact of the $8.2 \mathrm{ka}$ event on the expansion of first agricultural societies in the Mediterranean area. A review of palaeoclimatic and geo-archaeological data allows the authors to define a complex climatic pattern associated with this event in the Mediterranean area, and to observe frequent cultural gaps in cave infillings from Greece to Spain between 8500 and $8000 \mathrm{cal} \mathrm{BP}$, as well as a spatial redistribution of sites at the PPNB-NC/Yarmoukian transition in the Near East. However, they also point to the necessity, before relating cultural dynamics to environmental and climatic changes, of establishing well-dated, high-resolution sequences of events for history of both environment and societies.

The contribution by C. Delhon et al. focuses on the middle Neolithic period in the middle Rhone valley. Using a strategy based on the study of botanical remains not only from archaeological sites but also from 'off-site' sediment sequences in various depositional contexts (alluvial plains, karst caves, pedogenetic sequences), the authors describe a complex agro-sylvo-pastoral system with a marked specialisation in the exploitation of different parts in the landscape (plains versus slopes). Despite a strong and continuous pressure on the vegetation and soils between 6500 and $4500 \mathrm{cal} \mathrm{BP}$, the maintenance of such a fragile system over one millennium has been probably supported by favourable climatic conditions, and its collapse coincided with the development of cooler and wetter conditions at the beginning of the Neoglaciation.

On the basis of pollen data, M.J. Iriarte reports on the Holocene environmental history of the central sector of the Northern Iberian peninsula. In contrast to former theories, the results show that there are no relevant chronological differences in the record of first agricultural activities between the Atlantic and Mediterranean watersheds (ca. 8th-7th millennia BP). Next, the Bronze and Iron ages coincided with a clear increase in human impact. The apparent stronger environmental deterioration in the Mediterranean than in the Atlantic watershed does not necessarily mean a more intensive human use, but more probably it reflects a greater sensitivity of Mediterranean ecosystems and their difficulties to regenerate after human impact. 
The paper by A. Martinez-Cortizas et al. describes environmental changes in NW Iberia from 9000 to $2500 \mathrm{cal}$ BP. Various types of archives and proxies are used to reconstruct climate, vegetation, soils, and human impact. Climate seems to have been the most important driving force of environmental change until $7000 \mathrm{cal}$ BP. The earliest evidences of significant human impact date to ca. 7000-6500 cal BP (soil erosion, regression of forest). Cooler and drier climatic conditions after ca. $5500 \mathrm{cal}$ BP (Neoglaciation) and a stronger human impact since ca. $3500 \mathrm{cal}$ BP (beginning of the Middle Bronze age) resulted in an acceleration of environmental degradation. The authors conclude that the most critical conditions for environment occurred in abrupt climatic changes, probably due to an increase in both environmental fragility and human pressure.

The paper by J. Lopez-Saez et al. arrives at similar conclusions. It combines pollen and archaeological data to analyse the ecological crisis that affected the Ambles valley in central Spain during ca. 2800-2710 cal BP. Given the general biogeographical context and the strong human pressure during the late Bronze age (before $2800 \mathrm{cal} \mathrm{BP}$ ), which has weakened the regenerative capacity of vegetation, the sudden and abrupt climatic change (from xeric and warm conditions to more humid and cooler ones) resulted in drastic consequences for environment, while early Iron age settlements moved to the Northern Plateau.

Finally, both the papers by M. Magny et al. and by E. Gauthier and H. Richard focus on the Bronze and early Iron ages at Lake Bourget (NW Alps, France). Pollen records and quantitative reconstruction of climatic parameters using pollen and lake-level data suggest correlations between climate reversals (cooler and wetter conditions) during the middle Bronze and the early Iron ages, decreases in human impact on the vegetation around Lake Bourget, and a regional abandonment of lake dwellings. However, archaeological data collected in the region Franche-Comte (Jura Mountains, eastern France) show a general expansion of population density from the middle Bronze age to the early Iron age without apparent impact of climate changes. Thus, far from deterministic interpretation, this suggests a relative emancipation of protohistoric societies from climatic conditions, probably in relation to the spread of new modes of social and economic organisation. Such observations also invite caution when proposing general interpretation from single site.

To conclude, the nine papers in this volume suggest various remarks relative to further investigations for a deeper understanding of complex interactions between climate and human factors behind the Holocene environmental changes as follows:

- The improvement of time control appears to be a prerequisite to establish high-resolution well-dated sequences of events on a regional scale not only for changes in environment and climate (palaeoenvironmental and palaeoclimatic studies), but also for history of societies (archaeological investigations). This is the condition for fruitful inter-regional correlations between palaeoenvironmental and palaeoclimatic records, for instance on the scale of the Mediterranean area, as well as for regional comparisons between archaeological and palaeoenvironmental data.

- Strategies based on multi-proxy approaches seem to be the most appropriate to establish complex responses of environment to climatic changes and human impact. In addition to quantitative reconstruction of climatic parameters, they also appear to be the best way for the reconstruction of seasonality processes, i.e. a crucial factor for ecosystems as well as for first agricultural societies.

- In geo-archaeological studies, innovative strategies taking into account the collection of data not only from archaeological sites, but also from 'off-site' sediment sequences provide comprehensive data sets that seem more pertinent (i) to avoid cultural bias in the data (anthropogenic selection) and (ii) to understand complex management of landscapes by Neolithic and Protohistoric societies.

- Finally, regional archaeological data sets provide information about settlements, subsistence strategies, and population density of Neolithic and Protohistoric societies. From the perspective of a better understanding

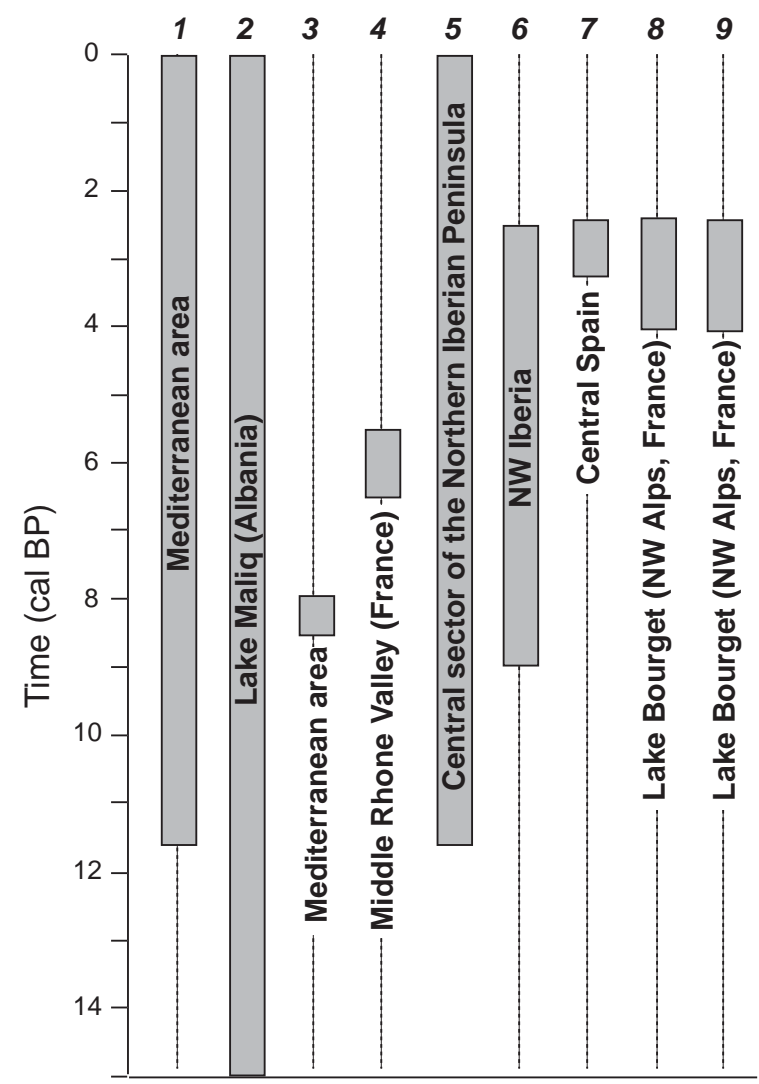

Fig. 1. Time windows and areas documented by the nine contributions in this volume. 1: G. Jalut; 2: A. Bordon et al.; 3: J.F. Berger and J. Guilaine; 4: C. Delhon et al.; 5: M.J. Iriarte; 6: A. Martinez-Cortizas et al.; 7: J. Lopez-Saez et al.; 8: M. Magny et al.; 9: E. Gauthier and Hervé Richard. 
of interactions between environment and societies, it seems crucial to develop approaches and projects that combine palaeoclimatic, palaeoenvironmental, and archaeological studies (Fig. 1).

Didier Galop* Laurent Carozza

Université Toulouse Le Mirail, Laboratoire GEODE UMR 5602 CNRS, 5 allées A. Machado, 31058 Toulouse Cedex, France E-mail address: didier.galop@univ-tlse2.fr (D. Galop)
Michel Magny Faculté des Sciences et Techniques, Laboratoire ChronoEnvironnement UMR 6249 CNRS, 16 route de Gray, 25030 Besançon Cedex, France

Jean Guilaine Collège de France, 11 Place Marcelin Berthelot, 75005 Paris, France

\footnotetext{
${ }^{*}$ Corresponding author. Tel.: +33561502 .
} 